\title{
Use of the Valsalva graft and long-term follow-up
}

\author{
Ruggero De Paulis, MD, ${ }^{\mathrm{a}}$ Raffaele Scaffa, MD, ${ }^{\mathrm{a}}$ Saverio Nardella, MD, ${ }^{\mathrm{a}}$ Daniele Maselli, MD, ${ }^{\mathrm{a}}$ \\ Luca Weltert, MD, ${ }^{\mathrm{a}}$ Fabio Bertoldo, MD, ${ }^{\mathrm{b}}$ Davide Pacini, MD, ${ }^{\mathrm{c}}$ Fabrizio Settepani, MD, ${ }^{\mathrm{d}}$ \\ Giuseppe Tarelli, MD, ${ }^{\mathrm{d}}$ Roberto Gallotti, MD, ${ }^{\mathrm{d}}$ Roberto Di Bartolomeo, MD,${ }^{\mathrm{c}}$ and Luigi Chiariello, $\mathrm{MD}^{\mathrm{b}}$
}

Objective: The Valsalva graft is a specifically designed Dacron graft that, on implantation and pressurization, generates pseudosinuses of Valsalva. We reviewed a multicenter experience of the reimplantation procedure with the Valsalva graft in patients with aneurysms involving the aortic root.

Methods: A total of 278 patients underwent valve-sparing aortic root replacement using the Valsalva graft at 4 different Italian cardiac surgery centers and were studied by clinical assessment and echocardiography. Of the 278 patients, 220 were men $(79 \%)$, with a mean age of $56 \pm 15$ years. Of the patients, $42(15 \%)$ had Marfan syndrome, $31(11 \%)$ had a bicuspid aortic valve, $13(5 \%)$ had acute aortic dissection, and $136(49 \%)$ had grade 3 or $4+$ aortic insufficiency. Concomitant cardiac procedures were performed in 78 patients $(28 \%)$. Additional aortic leaflet repair was necessary in 25 patients $(9 \%)$. The mean crossclamp time was $120 \pm 27$ minutes.

Results: There were $5(1.8 \%)$ operative and $5(1.8 \%)$ late deaths. The mean follow-up was $52 \pm 28$ months (range, 2-112 months) and was 100\% complete. The cumulative actuarial survival was $95.2 \%$ (268 patients). A total of 32 patients $(11 \%)$ had grade 3 to $4+$ aortic insufficiency, and 17 of these required late aortic valve replacement (range, 3-78 months). At 10 years of follow-up, the freedom from aortic valve reoperation rate was $91 \%$, and the rate of freedom from residual aortic insufficiency not needing reoperation was $88 \%$.

Conclusions: The reimplantation type of valve-sparing procedure can be facilitated by the use of the Valsalva graft and can be performed with satisfactory perioperative and midterm results. How an optimal root reconstruction will affect the second decade of follow-up has yet to be determined. (J Thorac Cardiovasc Surg 2010;140:S23-7)

Aortic valve-sparing procedures have gained popularity in recent years because of the better knowledge of aortic root physiology and the encouraging medium and long-term results that have been reported. In particular, the reimplantation type of valve-sparing procedure is the most commonly used technique, with satisfactory long-term results, not only in the general population, ${ }^{1-3}$ but also in those with Marfan syndrome $^{4-7}$ and in the pediatric population. ${ }^{8}$ The original reimplantation technique as described by David and Fein$\operatorname{del}^{9}$ has undergone a series of technical modifications ${ }^{10-13}$ to achieve the optimal sinus of Valsalva reconstruction that is crucial to achieving improved function of the reimplanted valve. Since February 2000, when it first became available, ${ }^{14}$ we have been using the Valsalva graft for the reimplantation procedure, without major modifications to the original technique. This is a Dacron graft with

\footnotetext{
From the Departments of Cardiac Surgery, ${ }^{\text {a }}$ European Hospital, Rome, Italy; University of Tor Vergata, ${ }^{\mathrm{b}}$ Rome, Italy; University of Bologna, ${ }^{\mathrm{c}}$ Bologna, Italy; and Istituto Humanitas, ${ }^{\mathrm{d}}$ Rozzano, Italy.

Disclosures: Ruggero De Paulis receives royalties from Vascutek Terumo. Raffaele Scaffa, Saverio Nardella, Daniele Maselli, Luca Weltert, Fabio Bertoldo, Davide Pacini, Fabrizio Settepani, Giuseppe Tarelli, Roberto Gallotti, Roberto Di Bartolomeo, and Luigi Chiariello have nothing to disclose with regard to commercial support. Received for publication April 22, 2010; accepted for publication July 22, 2010.

Address for reprints: Ruggero De Paulis, MD, Department of Cardiac Surgery, European Hospital, Via Portuense 700, Rome 00149 Italy (E-mail: depauli@tin.it). $0022-5223 / \$ 36.00$

Copyright (C) 2010 by The American Association for Thoracic Surgery doi:10.1016/j.jtcvs.2010.07.060
}

a specific design that, on implantation and pressurization, generates 3 independent pseudosinuses, contributing to the simplification and standardization of the whole procedure.

In the present report, we describe our experience with the Valsalva graft in the reimplantation procedure and analyze the long-term results.

\section{METHODS}

From May 2000 to October 2009, a total of 278 patients underwent a reimplantation type of valve-sparing procedure at 4 major cardiac surgery centers in Italy (the European Hospital of Rome, the University of Tor Vergata of Rome, the University of Bologna, and the Humanitas Institute of Rozzano). Because of the mutual training among the 4 centers, the surgical technique was virtually the same throughout the whole period. The surgical technique has been previously described in detail. ${ }^{15}$ In brief, after excising the aortic sinuses, a Valsalva graft of an appropriate size was secured to the aortic annulus using pledgeted sutures passed on a horizontal plane below the aortic cusps. Next, the valve was sutured inside the conduit using 3 continuous sutures just above the insertion of the aortic cusp in a scalloped fashion. Coronary ostial anastomoses in the corresponding sinus and the distal aortic anastomosis completed the procedure. The conduit size was chosen by adding $5 \mathrm{~mm}$ to the size of the annulus or to the size of the sinotubular (ST) junction, in the case of annulo-aortic ectasia. The height of the new root was adapted to each particular patient's anatomy, ensuring that the top of the commissures was at the level of the new ST junction.

\section{Patient Demographics}

The patients were predominantly men, with a mean age of $55.6 \pm 14.7$ years (range, 14-83 years). Preoperatively, absent-to-mild aortic insufficiency (AI) was observed in $67(24 \%)$ of the 278 patients, and moderate-to-severe 


\section{Abbreviations and Acronyms \\ $\mathrm{AI}=$ aortic insufficiency \\ $\mathrm{AVR}=$ aortic valve replacement \\ $\mathrm{ST}=$ sinotubular}

AI was present in 136 patients (48.7\%). Most patients had normal left ventricular function, and $80 \%$ of patients had New York Heart Association functional class I or II. The mean aortic root diameter was $48.9 \pm 8.2 \mathrm{~mm}$. A bicuspid aortic valve was present in 31 patients $(11.1 \%)$, and 42 patients $(15.1 \%)$ had Marfan syndrome according to the Ghent criteria; 13 patients $(4.7 \%)$ underwent surgery for acute aortic dissection. The mean follow-up was $52 \pm 28$ months (range, 2-112 months). No patient was lost to followup. The patients were followed by the referring cardiologists and were interviewed annually. All patients had undergone an echocardiographic study during the last year of follow-up, which was closed at the end of December 2009. Residual AI, if present, was reported and graded as none or trivial, mild, moderate, or severe.

\section{Statistical Analysis}

The study was designed as a mortality-morbidity project in a multicenter prospective nonrandomized study. One main investigator, who was responsible for data completeness and accuracy, was designated for each center. The preoperative data were collected at surgery and stored in both paper files and a local database. The intraoperative data were included in the files and databases directly by the surgeons performing the operation. Follow-up produced both echocardiographic and clinical data. Visits were conducted every year, and the data were added to the original paper and database files. All data processing was performed independently by a statistician not involved in the data collection process on a workstation running IBMcompatible Statistical Package for Social Sciences, version 17.0 (SPSS, Chicago, Ill) on a Windows 7 machine.

The data are reported as the mean \pm standard deviation for continuous variables and as the absolute number and relative incidence for categorical variables. Mortality and morbidity are presented as the actuarial incidence, and all plots were determined using the Kaplan-Meier method. All variables were first tested by nontime-dependent univariate regression analysis, and then binary or multinomial logistic regression models were used. All significant variables producing a correlation between mortality or morbidity and the covariates were tested using the Cox regression model. To increase the robustness of the analysis, the results were also compared using the TaroneWare and Breslow models.

\section{RESULTS \\ Early Outcomes}

There were 5 operative deaths (1.8\%): 3 patients died of multiple organ failure after surgery for acute aortic dissection; 1 of bowel ischemia secondary to a huge inguinal hernia, and 1 of intestinal ischemia caused by a postoperative type B aortic dissection. The in-hospital mortality rate was significantly greater in the first triennium of experience than in the second and third $(8 / 100[8 \%]$ vs $1 / 95[1 \%]$ vs $1 / 82[1 \%]$, respectively; $P=.03$ ). The mean cardiopulmonary bypass time was $144 \pm 38$ minutes (range, 90-373 minutes), with a mean aortic crossclamp time of $120 \pm 27$ minutes (range, 67-271 minutes). Concomitant procedures (mitral valve surgery and/or coronary artery bypass grafting and/or atrial septal defect repair) were performed in $28 \%$ of the cases. Additional valve cusp repair was performed in 25 patients $(9 \%)$, and 9 patients $(3.2 \%)$ required re-exploration for bleeding.

\section{Late Outcomes}

Five patients $(1.8 \%)$ died during follow-up: 3 of cardiovascular causes (chronic heart failure in 1, pulmonary embolism in 1 , and cerebral stroke in 1) and 2 of noncardiovascular causes (cancer). At 10 years of follow-up, the overall survival rate was $95.2 \%$ (Figure 1). The only independent predictor of death was the presence of acute aortic dissection (hazard ratio $2.1 ; P=.003$ ).

The 10-year rate of freedom from reoperation on the aortic valve was $91 \%$ (17 patients underwent aortic valve replacement $[\mathrm{AVR}]$ ) and was equally distributed among the centers (Figure 2). All patients survived reoperation. The incidence of reoperation was significantly greater among the patients who had undergone additional valve cusp repair (hazard ratio $1.67 ; P=.0036)$ and among those who had undergone surgery for acute aortic dissection (hazard ratio $2.4 ; \mathrm{P}<.001$ ). In contrast, the presence of bicuspid aortic valve, Marfan syndrome, and preoperative moderate-to-severe AI did not influence the need for AVR. In the remaining patients, the 10-year rate of freedom from residual AI was $88 \%$ (15 patients had residual AI not requiring redo surgery; Figure 3). The 10year rate of freedom from moderate-to-severe AI for the patients with Marfan syndrome was $93.5 \%$ and for those without Marfan syndrome, $87.1 \%(P=.46)$. No pre- or intraoperative predictors of postoperative residual AI were found. The patients who had undergone surgery in the first 5 years of experience for each center showed a tendency toward a greater incidence of residual AI or the need for reoperation compared with those treated in the subsequent years (14\% [26/186] vs 7\% [6/82]).

Considering the combined endpoint of AVR plus residual AI, 32 patients ( $12 \%$ of the survivors) had unsatisfactory results.

A less-than-perfect postoperative result, as indicated by the transesophageal echocardiographic findings, had the strongest influence on the long-term incidence of functionally unsatisfactory results (need for AVR and/or residual AI). Greater-than-trivial residual AI in the early postoperative period consistently progressed to a more severe grade during follow-up. The actuarial rate of freedom from the combined endpoint (need for AVR and residual AI) in patients with or without residual $\mathrm{AI}$ in the early postoperative period was $28 \%(17 / 67)$ versus $89 \%(15 / 212 ; P<.001$; Figure 4).

\section{DISCUSSION}

In the past few years, the reimplantation type of aortic valve-sparing procedure has gained increasing acceptance over the remodeling type because of its better long-term 


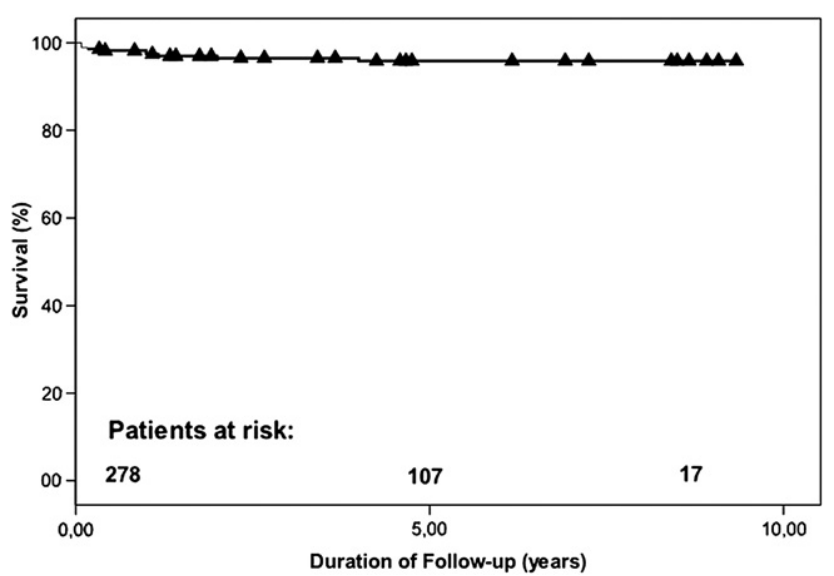

FIGURE 1. Overall actuarial survival for all patients. Survival rate was $95.2 \%$ at both 5 and 10 years of follow-up.

results. ${ }^{1}$ The progressive increase in aortic annular diameter over time has been the main reason for the unsatisfactory long-term results of the remodeling technique, especially for patients with degenerative diseases such as Marfan syndrome. ${ }^{16}$ Whether a noncompliant Dacron graft will also induce progressive annular ectasia in an otherwise normal subject has yet to be determined and is still a matter of debate. Nonetheless, the remodeling technique remains an excellent option because of its optimal anatomic root reconstruction and its physiology-preserving approach. ${ }^{17}$

However, the original reimplantation technique, as described by David and Feindel, ${ }^{9}$ in the early 1990s, lacked proper sinus reconstruction, with a potential detrimental effect on leaflet motion and, consequently, on long-term durability. The past 10 years have witnessed great efforts in modifying this technique to achieve a somewhat better reconstruction of the sinuses while maintaining the desired goals of annular stabilization, good support of the aortic wall, and optimal hemostasis. Of the many different techniques proposed for the creation of pseudosinuses, ${ }^{18,19}$

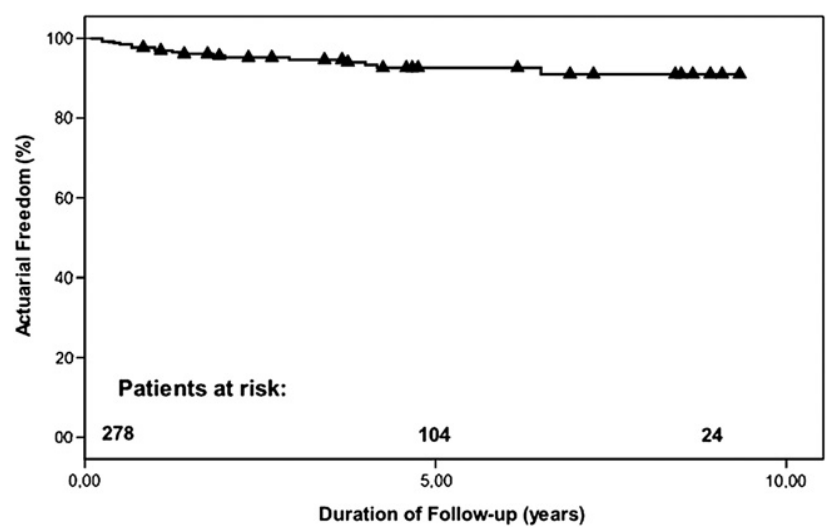

FIGURE 2. Actuarial freedom from late aortic valve replacement. It was $92.6 \%$ at 5 years and $91 \%$ at 10 years.

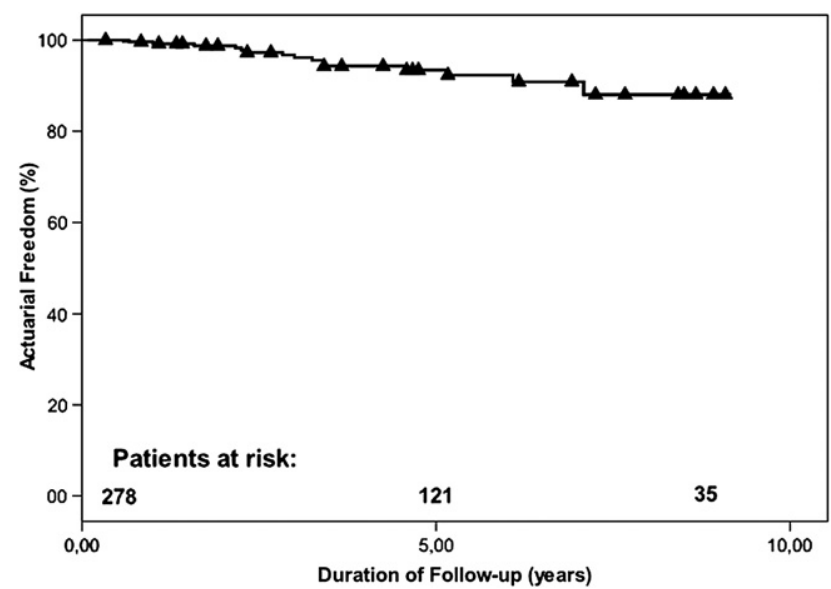

FIGURE 3. Actuarial freedom from residual significant aortic regurgitation rate. It was $93.4 \%$ at 5 years and $88 \%$ at 10 years.

the most frequently used have been the David V or its Stanford modification, ${ }^{12}$ in which a larger-than-needed graft is selected and is then pinched down at the level of the annulus and the ST junction to create a bulge at the level of the sinuses, or similar variations, such as described by Takamoto and colleagues ${ }^{13}$ and Rama and colleagues. ${ }^{20}$

Since May 2000, when it first became available, we have been using the Valsalva graft, which, on implantation and pressurization, generates pseudosinuses without the need for any substantial variation in the original reimplantation technique. ${ }^{14}$ The peculiar design of the Valsalva graft allows for proper root reconstruction by re-establishing the main root characteristics: 2 rings (annulus and ST junction), joined by 3 pillars (the commissures), separating 3 independent bulging sinuses. The portion of Dacron behind the commissures is maintained at an inner plane with respect to the

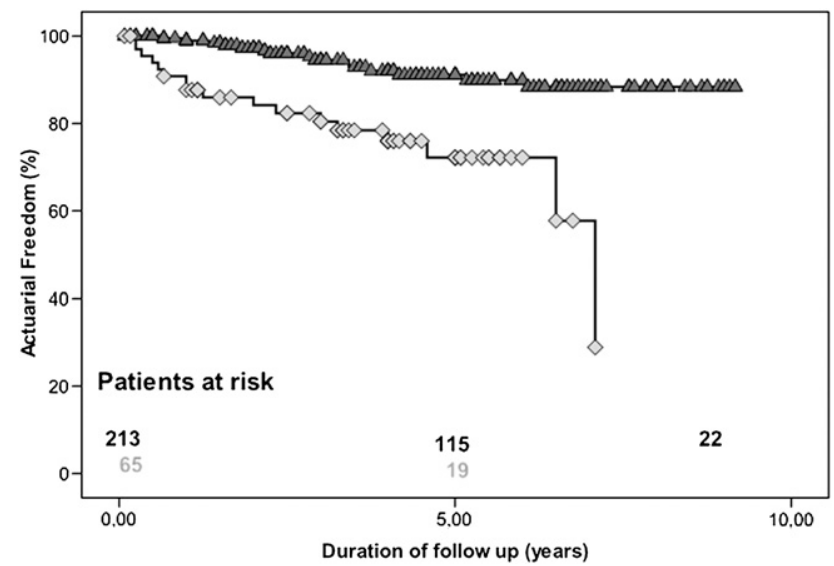

FIGURE 4. Actuarial 10-year rate of freedom from combined residual significant aortic regurgitation and aortic valve replacement was $89 \%$ in patients with optimal echocardiographic function of reimplanted aortic valve early postoperatively but $28 \%$ in patients who were left with imperfect function of reimplanted valve $(P=.001)$. 
rest of the root. The peculiar graft design also makes it possible to adapt it to each individual anatomy and not vice versa. Any geometric asymmetry in the cusps and sinuses (with the bicuspid valve representing the most extreme case) is well respected and reproduced by the graft.

For these reasons, together with the need for standardization and reproducibility of the procedure, we have been using this approach exclusively and have followed our patients for the past 10 years. Because of the relatively low number of valve-sparing procedures performed annually at each center, we designed a multicenter study involving 4 different centers using the same surgical approach. The technique was shown by 1 surgeon directly to the colleagues of the second center and then by another surgeon to the next center, thus ensuring a level of homogeneity in the various steps of the operation, from graft size selection to graft-patient matching. At least 8 different surgeons directly performed most of the operations. Thus, the goal we achieved was twofold: procedural standardization by the reduced need for specific artistic surgical skills and reproducibility, as assessed by the different surgeons involved in the present study. In most cases, valve-sparing procedures have been reported from a single center and, quite often, from the experience of a single surgeon, reducing the applicability of the results on a larger scale. ${ }^{1,3}$ To our knowledge, this is one of the largest studies reporting on the long-term results of a single type of valve-sparing procedure.

The first conclusion that can be drawn from such a study is that this type of operation is safe and results in very low operative mortality, as recently confirmed by Volguina and colleagues $^{6}$ in a multicenter trial comparing the Bentall procedure with the valve-sparing procedure. The second conclusion is that once a patient leaves the operating room with no or trivial residual AI, the result is stable for a long period. The great majority of patients who required a reoperation or who experienced progressive worsening of the degree of AI were those with a suboptimal result at the first operation (Figure 4). This observation was also supported by data from Kallenbach and colleagues, ${ }^{2}$ who reported long-term follow-up with the standard David I procedure and found that all reoperations occurred within the first year of follow-up. Our findings have also indicated that a patient should not leave the operating room with a greater than $1+$ residual AI and that the valve should immediately be replaced. As an alternative, additional repair on the leaflets should be performed, remembering, however, that any leaflet plasty has a greater risk of early or late failure.

The presence of leaflet prolapse causing residual $\mathrm{AI}$ at the end of a reimplantation procedure can be due to either an overlooked problem at valve assessment or valve distortion induced by the surgeon when suturing the valve inside the conduit. Needless to say, if we accept leaflet plasty as a part of the valve-sparing procedure, an increased number of valves could be spared. However, we are adding an important variable that might have an important role in the durability of the valve. In our experience, a significant number of patients who had received some form of leaflet plasty also had a significant incidence of residual AI. Similarly, Hanke and colleagues, ${ }^{21}$ in a recent analysis of the 2 most common aortic valve-sparing techniques-remodeling and reimplantation-found that concomitant cusp intervention was associated with a significant increase in residual AI over time in both groups. We strongly believe that when comparing 2 different types of valve-sparing procedures, only patients with normal leaflets (i.e., no intrinsic leaflet lesions) should be selected and followed for a long period.

The third observation is that this type of operation works equally well for patients with and without Marfan syndrome. Our findings are in line with those recently reported by $\mathrm{Da}-$ vid and colleagues ${ }^{4}$ of a large group of patients with Marfan syndrome and with those reported by Cameron and colleagues, ${ }^{7}$ in a pediatric population, including a large number of patients with Marfan syndrome. Although the numbers were too small for a strong meaningful conclusion, our results also suggest that a bicuspid valve can be reimplanted as safely as a tricuspid valve.

Finally, the last observation is that the degree of preoperative AI had little effect on valve durability. Similar to our findings, other investigators ${ }^{22}$ did not found a correlation between the root diameter and the durability of the reimplanted valve. Nonetheless, it is evident that operating at a smaller root diameter increases the chance of finding more normal leaflets.

It might be true that for patients without degenerative disease and with a nondilated annulus, a remodeling type of valve-sparing procedure could also be a good option, especially because of optimal sinus reconstruction and better root dynamics. ${ }^{21}$ The ability of the Valsalva graft to provide 3 independent sinuses of normal shape and dimension makes the reimplantation procedure applicable to virtually every patient. This in turn will result in improved standardization and greater reproducibility of the results.

A multicenter study has some advantages and some disadvantages. The study was started in the early 2000s when each center had to build its learning curve, not only in the use of the graft, but also, more importantly, in the reimplantation procedure. At that time, only a very few valve reimplantation procedures had been performed in Italy. The evidence from our data has shown how the cases that needed reoperation —or had registered significant residual aortic valve regurgitation-were those performed in the first phase of our experience, when the assessment of intrinsic leaflet prolapse was underevaluated and a certain degree of residual AI was accepted and deemed tolerable.

However, a multicenter study also provides the unique opportunity of evaluating whether a procedure can guarantee standard results, even across different centers and when performed by different surgeons. The use of the Valsalva graft 
has guaranteed good standardization of the procedure because the reconstruction of pseudosinuses of Valsalva does not require any major modification to the original and well-standardized procedure. In contrast, all other techniques are somewhat more demanding and require specific skills of the surgeon in judging the proper sinus reconstruction in terms of shape, depth, and size and to avoid distortion of the annulus or the commissures. In contrast, on pressurization of a Valsalva graft, the sinus will automatically take shape between the 3 commissures, and the portion of Dacron behind the commissures is maintained at an inner plane with respect to the rest of the root.

\section{Study Limitations}

This was a retrospective multicenter study, with the several limitations typical of such studies. Given the relative complexity of the surgical procedure and the numbers of surgeons involved, potential bias might have been introduced and gone undetected by our analysis. Although the great majority of echocardiograms were done at each referring center, a small number of examinations were gathered from the referring cardiologists. These were included in the database only if they did not report significant residual AI or any unusual abnormality. Otherwise, the examination was repeated to confirm the findings.

The decision of whether to accept an imperfect result or add a leaflet plasty or immediately replace the valve might have been different in the different centers, and this might have somehow influenced the results. However, this was a part of the learning curve of each individual surgeon and should be considered a necessary step toward the good reproducibility of the results.

\section{References}

1. David TE, Feindel CM, Webb GD, Colman JM, Armstrong S, Maganti M. Aortic valve preservation in patients with aortic root aneurysm: results of the reimplantation technique. Ann Thorac Surg. 2007;83:S732-90.

2. Kallenbach K, Karck M, Pak D, Salcher R, Khaladj N, Leyh R, et al. Decade of aortic valve sparing reimplantation: are we pushing the limits too far? Circulation. 2005;30:112(9 Suppl):1253-9.

3. de Kerchove L, Boodhwani M, Glineur D, Poncelet A, Verhelst R, Astarci P, et al. Effects of preoperative aortic insufficiency on outcome after aortic valve-sparing surgery. Circulation. 2009;120(11 Suppl):S120-6.
4. David TE, Armstrong S, Maganti M, Colman J, Bradley TJ. Long-term results of aortic valve-sparing operations in patients with Marfan syndrome. J Thorac Cardiovasc Surg. 2009;138:859-64.

5. Settepani F, Szeto WY, Pacini D, de Paulis R, Chiariello L, di Bartolomeo R, et al. Reimplantation valve-sparing aortic root replacement in Marfan syndrome using the Valsalva conduit: an intercontinental multicenter study. Ann Thorac Surg. 2007;83:S769-90.

6. Volguina IV, Miller DC, LeMaire SA, Palmero LC, Wang XL, Connolly HM, et al. Aortic valve operative outcomes in Marfan patients study group: valvesparing and valve-replacing techniques for aortic root replacement in patients with Marfan syndrome: analysis of early outcome. J Thorac Cardiovasc Surg. 2009; 137:1124-32.

7. Cameron DE, Alejo DE, Patel ND, Nwakanma LU, Weiss ES, Vricella LA, et al. Aortic root replacement in 372 Marfan patients: evolution of operative repair over 30 years. Ann Thorac Surg. 2009;87:1344-50.

8. Vricella LA, Williams JA, Ravekes WJ, Holmes KW, Dietz HC, Gott VL, et al. Early experience with valve-sparing aortic root replacement in children. Ann Thorac Surg. 2005;80:1622-7.

9. David TE, Feindel CM. An aortic valve-sparing operation for patients with aortic incompetence and aneurysm of the ascending aorta. J Thorac Cardiovasc Surg. 1992; 103:617-22.

10. David TE. Aortic valve sparing operations. Ann Thorac Surg. 2002;73:1029-30

11. Moritz A, Risteski P, Dogan S, Macit H, Akbulut B, Zierer A, et al. Six stitches to create a neosinus in David-type aortic root resuspension. $J$ Thorac Cardiovasc Surg. 2007;133:560-2.

12. Demers P, Miller DC. Simple modification of "T. David-V", valve-sparing aortic root replacement to create graft pseudosinuses. Ann Thorac Surg. 2004;78:1479-81.

13. Takamoto S, Nawata K, Morota T. A simple modification of "David-V", aortic root reimplantation. Eur J Cardiothorac Surg. 2006;30:560-2.

14. De Paulis R, De Matteis GM, Nardi P, Scaffa R, Colella DF, Chiarello L. A new aortic Dacron conduit for surgical treatment of aortic root pathology. Ital Heart J. 2000;1:457-63.

15. De Paulis R, Scaffa R, Forlani S, Chiariello L. The Valsalva graft in aortic valve repair and replacement. Multimedial Manual of Cardio Thoracic Surgery. November 29, 2005; doi:10.1510/mmcts.2004.000992.

16. Bethea BT, Fitton TP, Alejo DE, Barreiro CJ, Cattaneo SM, Dietz HC, et al. Results of aortic valve-sparing operations: experience with remodeling and reimplantation procedures in 65 patients. Ann Thorac Surg. 2004;78:767-72.

17. Leyh RG, Schmidtke C, Sievers HH, Yacoub MH. Opening and closing characteristics of the aortic valve after different types of valve-preserving surgery. Circulation. 1999;23;100:2153-60.

18. Cochran RP, Kunzelman KS, Eddy AC, Hofer BO, Verrier ED. Modified conduit preparation creates a pseudosinus in an aortic valve-sparing procedure for aneurysm of the ascending aorta. J Thorac Cardiovasc Surg. 1995;109:1049-58.

19. Gleason TG. New graft formulation and modification of the David reimplantation technique. J Thorac Cardiovasc Surg. 2005;130:601-3.

20. Rama A, Rubin S, Bonnet N, Gandjbakhch I. New technique of aortic root reconstruction with aortic valve annuloplasty in ascending aortic aneurysm. Ann Thorac Surg. 2007;83:1908-10.

21. Hanke T, Charitos EI, Stierle U, Robinson D, Gorski A, Sievers HH, et al. Factors associated with the development of aortic valve regurgitation over time after two different techniques of valve-sparing aortic root surgery. $J$ Thorac Cardiovasc Surg. 2009; 137:314-9.

22. Leyh RG, Kallenbach K, Karck M, Hagl C, Fischer S, Haverich A. Impact of preoperative aortic root diameter on long-term aortic valve function after valve sparing aortic root reimplantation. Circulation. 2003;108(Suppl 1):II285-90. 